\title{
Association of Metabolic Syndrome with Albuminuria in Diabetes Mellitus Type 2
}

\author{
Husin Thamrin ${ }^{*}$, Ari Sutjahjo1, Agung Pranoto', Soebagijo Adi Soelistijo ${ }^{1}$ \\ ${ }^{1}$ Department of Internal Medicine, Faculty of Medicine, Universitas Airlangga - Dr. Soetomo General Hospital Surabaya, \\ Indonesia.
}

\section{A R T I C L E I N F O}

\section{Article history:}

Received 23 August 2019

Received in revised form 14

October 2019

Accepted 21 October 2019

Available online 31 October 2019

\section{Keywords:}

Metabolic Syndrome,

Albuminuria,

Diabetes Mellitus Type 2.

*) Corresponding author:

drthamrin1@gmail.com

\begin{abstract}
A B S T R A C T
Introduction: Metabolic syndrome is a risk factor for cardiovascular disease as well as the occurrence of chronic kidney disease. According to IDF, metabolic syndrome is diagnosed when central obesity has two or more metabolic abnormalities. Several previous studies reported an significant association found between the metabolic syndrome with albuminuria. In Indonesia, association of metabolic syndrome with albuminuria in type 2 diabetes have not been reported yet. The aims of this study was to analyze the association of metabolic syndrome with albuminuria in type 2 diabetes patients.

Methods: This was an analytic observational study with cross-sectional design. 131 diabetes mellitus type 2 patients were taken as sample. Data was analyzed using Spearman Correlation and Mann-Whitney test. Significance level used was 0.05.

Results: From 131 subjects with metabolic syndrome, normoalbuminuria proportion was $65.4 \%$, microalbuminuria $27.1 \%$, and macroalbuminuria $7.5 \%$. There was significant association between systolic blood pressure with albuminuria, $\mathrm{p}=0.000, \mathrm{r}=0.325$. Fasting blood glucose with albuminuria, $\mathrm{p}=0.01, \mathrm{r}=0.223$, but no significant association between diastolic blood pressure with albuminuria was found with $\mathrm{p}=0.153, \mathrm{r}=0.125$, waist circumference with albuminuria, $p=0.311, r=0.089$, low HDL with albuminuria $p=0.771, r=-$ 0.025 . Hypertriglyceridemia with albuminuria, $\mathrm{p}=0.727$ and $\mathrm{r}=0,031$.

Conclusion: The results indicate a strong association between the components of metabolic syndrome especially systolic blood pressure and fasting blood glucose with albuminuria. Whereas in diastolic blood pressure, waist circumference, low HDL, and hypertriglyceridemia no significant associations found
\end{abstract}

\begin{abstract}
Introduction
Metabolic syndrome is a major health problem nowadays. International Diabetes Federation (IDF) believes that groups of these factors influence the global epidemic of diabetes mellitus type 2 (DMT2) and cardiovascular disease, the syndrome consists of several risk factors including visceral obesity, dyslipidemia, insulin resistance, impaired glucose tolerance, and increased blood pressure. ${ }^{1}$ The disease is related to lifestyle such as physical inactivity, junk food, carbohydrates, and smoking.

Metabolic syndrome affects about $40 \%$ of the population above 50 years old in United States and almost $30 \%$ in Europe. Tjokroprawiro reported that the prevalence of metabolic syndrome in a population over 40 years old undergoing a medical examination in Surabaya ranged from $32 \%$. In addition, it was reported $43.3 \%$ were treated in DMT2 and $59.0 \%$ were treated in naïve DMT2 as observed in private clinics, while
\end{abstract}

the prevalence of metabolic syndrome in people with DMT2 with obesity was $81.7 \%$. $^{2}$

Metabolic syndrome is closely related to cardiovascular disease (CVD). In addition, recent studies show an association between metabolic syndrome and the risk of chronic kidney disease (CKD) and microalbuminuria. ${ }^{3}$ Study of Hao, et al. (2006) explained that there was a significant correlation between metabolic syndrome and the prevalence of microalbuminuria $(\mathrm{r}=0.44, \mathrm{p}<0.001){ }^{4}$

Albuminuria is an early marker of CKD which also acts as a predictor of CVD and mortality. People with DMT2 with microalbuminuria, progression to massive proteinuria occurs in $20-40 \%$ of cases, while $10-50 \%$ of DMT2 patients with proteinuria will have CKD and require renal replacement therapy. ${ }^{2}$

The aim of this study was to determine the association between metabolic syndrome and albuminuria in people with DMT2 especially in Surabaya. It could give a 
little description of the prevalence and characteristics of metabolic syndrome in the population of type 2 diabetes, especially in Surabaya. In addition, to predict the possibility of diabetes patients with metabolic syndrome that have cardiovascular complications. Thus, the therapy can reduce the possibility of cardiovascular complications as early as possible.

\section{Methods}

This was an observational analytic study with cross sectional design. Population of this study was DMT2 patients over the age of 30 years old and less than 80 years old who undergo treatment at a private outpatient clinic Metabolic and Diabetes Endocrinologist Internist Consultant in Surabaya. The sample was 40 people, taken by using non random purposive sampling technique.

Independent variable was components of metabolic syndrom (waist size, triglyceride level, HDL level, systolic pressure, diastolic pressure, and fasting blood glucose level). Dependent variable was albuminuria, divided into normo albuminuria, mikro albuminuria, and makro albuminuria. The data was collected using medical record and was analyzed using Spearman Correlation and Mann-Whitney.

\section{Results}

\section{Demographic and Clinical Chracteristic}

The number of subjects included this study was 131 DMT2 patients, consisting of 71 men $(54.2 \%)$ and 62 women $(45.8 \%)$. The overall clinical characteristics of the subjects were summarized in Table 1. Median of age was 59 (minimum 31 - maximum 79) years old, median of body mass index (BMI) was 29.12 (minimum 22.48 - maximum 45.91) $\mathrm{kg} / \mathrm{m} 2$, median of systolic blood pressure was 130 (minimum 100 - maximum 170) $\mathrm{mmHg}$, diastolic blood pressure 80 (minimum 60 maximum 110) $\mathrm{mmHg}$, median of waist circumference was 95 (minimum 80 - maximum 121) cm, median of fasting blood glucose was 160 (minimum 65 - maximum 427) $\mathrm{mg} / \mathrm{dL}$, median of 2 hours post prandial glucose was 237 (minimum 104 - maximum 749) mg/dL, median HbA1C 8 (minimum 5 - maximum 18)\%, median cholesterol 198 (minimum 104 - maximum 318) mg/dL, median LDL 119 (minimum 48 - maximum 254) mg/ dL, median Triglyceride 153 (minimum 58 - maximum 484) $\mathrm{mg} / \mathrm{dL}$, median HDL 43 (minimum 13 - maximum 74) $\mathrm{mg} / \mathrm{dL}$, median $\mathrm{Hb} 14$ (minimum 10 - maximum 16.2 ) g/dL, median BUN 15 (minimum 5 - maximum 52) $\mathrm{mg} / \mathrm{dL}$, median serum creatinine 1 (Minimum 0.4 Maximum 1.3) mg/dL, and median Albuminuria (ACR) 14 (min imum 1 - maximum 1364) $\mu \mathrm{g} / \mathrm{mg}$ creat.

Table 1. Demographic and clinical characteristic

\begin{tabular}{lcccc}
\hline Variable & Unit & Median & Minimum & Maximum \\
\hline Age & year & 59 & 31 & 79 \\
\hline $\begin{array}{l}\text { Duration of } \\
\text { DM }\end{array}$ & year & 13 & 1 & 37 \\
\hline BMI & $\mathrm{kg} / \mathrm{m} 2$ & 29.12 & 22.48 & 45.91 \\
\hline Systolic BP & $\mathrm{mmHg}$ & 130 & 100 & 170 \\
\hline
\end{tabular}

\begin{tabular}{|c|c|c|c|c|}
\hline $\begin{array}{l}\text { Diastolic } \\
\text { BP }\end{array}$ & $\mathrm{mmHg}$ & 80 & 60 & 110 \\
\hline Waist size & $\mathrm{cm}$ & 95 & 80 & 121 \\
\hline $\begin{array}{l}\text { Fasting } \\
\text { Blood } \\
\text { Glucose } \\
\text { Level }\end{array}$ & $\mathrm{mg} / \mathrm{dL}$ & 160 & 65 & 427 \\
\hline $\begin{array}{l}\text { Post Prandi- } \\
\text { al Glucose } \\
\text { Level }\end{array}$ & $\mathrm{mg} / \mathrm{dL}$ & 237 & 104 & 749 \\
\hline $\mathrm{HbA} 1 \mathrm{C}$ & $\%$ & 8 & 5 & 18 \\
\hline $\begin{array}{l}\text { Total } \\
\text { Cholesterol }\end{array}$ & $\mathrm{mg} / \mathrm{dL}$ & 198 & 104 & 318 \\
\hline LDL & $\mathrm{mg} / \mathrm{dL}$ & 119 & 48 & 254 \\
\hline TG & $\mathrm{mg} / \mathrm{dL}$ & 153 & 58 & 484 \\
\hline HDL & $\mathrm{mg} / \mathrm{dL}$ & 43 & 13 & 74 \\
\hline $\mathrm{Hb}$ & $\mathrm{g} / \mathrm{dL}$ & 14 & 10 & 16.2 \\
\hline BUN & $\mathrm{mg} / \mathrm{dL}$ & 15 & 5 & 52 \\
\hline $\begin{array}{l}\text { Serum Cre- } \\
\text { atinin }\end{array}$ & $\mathrm{mg} / \mathrm{dL}$ & 1 & 0.4 & 1.3 \\
\hline $\begin{array}{l}\text { Albumin- } \\
\text { uria (ACR) }\end{array}$ & $\begin{array}{c}\mu \mathrm{g} / \mathrm{mg} \\
\text { kreat }\end{array}$ & 14 & 1 & 1364 \\
\hline
\end{tabular}

Profile of Metabolic Syndrome of the subjects

Profile of metabolic syndrome was classified by the components of the metabolic syndrome based on IDF criteria in 2006. From 131 subjects, the proportion of patients with 3 components of metabolic syndrome were $67(50.4 \%)$ people, patients with 4 components of metabolic syndrome were $47(35.3 \%)$ people, and patients with 5 components of metabolic syndrome were $19(14,3 \%)$ people, as seen in Figure 1.

Characteristics of DMT2 subjects based on classification of metabolic syndrome components are shown in Table 2. Due to the abnormal distribution of the data, non-parametric test calculation were used, and Kruskal Wallis test was chosen to compare more than 2 variables. This study found significant differences in systolic blood pressure with metabolic syndrome component group $\mathrm{p}=0.000$, diastole blood pressure $\mathrm{p}=0.000$, hypertriglyceridemia $\mathrm{p}=0.000$, low HDL $\mathrm{p}=0.000$, and albuminuria $\mathrm{p}=0.002$. Meanwhile, for age, duration of DM, body mass index, waist circumference, fasting blood glucose, post prandial glucose, HbA1C, total cholesterol, $\mathrm{LDL}, \mathrm{Hb}, \mathrm{BUN}$, and serum creatinine, there were no significant differences.

Due to the significant differences in systolic BP, diastolic BP, hypertriglyceride and low HDL with metabolic syndrome, further tests were performed with Mann-Whitney test to find out where the difference lies, whether in the 3 components group with 4 components, 3 components group with 5 components, or 4 components group with 5 components group of metabolic syndrome. Based on the Mann-Whitney test, there was a significant difference between 3 components group and 4 components of metabolic syndrome, $p=0.007$ in systolic BP, $p=0.000$ in diastolic $B P, p=0.000$ for hypertriglycerides, and $\mathrm{p}=0.001$ for low HDL. Between 
3 components group and 5 components, a significant difference was obtained with $\mathrm{p}=0.000$ in systolic BP, $\mathrm{p}=0.000$ in diastolic $\mathrm{BP}, \mathrm{p}=0.000$ for hypertriglyceride, and $\mathrm{p}=0.000$ for low HDL. Between groups of 4 components and 5 components of metabolic syndrome, a significant difference was obtained in systolic BP $(\mathrm{p}=0.001)$, whereas in diastolic BP, hypertriglyceride, and low HDL there were no significant differences.

Profile of albuminuria in patients with DM type 2 and metabolic syndrome

Albuminuria was classified based on Perkeni Consensus in 2006, consisting of normoalbuminuria, microalbuminuria, and macroalbuminuria. Albuminuria examination used ACR method. Subjects with normoalbuminuria were 87 (65.4\%) people, microalbuminuria were $36(27.1 \%)$ people, and macroalbuminuria were $10(7.5 \%)$ people.

Characteristics of DMT2 with metabolic syndrome based on albuminuria classification (normoalbuminuria, microalbuminuria, macroalbuminuria) can be seen in Table 3. A significant difference was found in systolic blood pressure with albuminuria $(p=0.024)$. Whereas in age, duration of DM, body mass index (BMI), diastolic blood pressure, waist circumference, fasting blood glucose (FBG), post prandial level, HbA1C, total cholesterol, LDL, triglycerides, HDL, Hb, BUN, and serum creatinine no meaningful difference obtained.

Due to the significant differences found in systolic BP, then further tests with the Mann-Whitney test was carried out. Based on the Mann-Whitney test, there was a significant difference between the normoalbuminuria and microalbuminuria groups $(p=0.007)$. However, between normoalbuminuria and macroalbuminuria groups, there was no significant difference $(p=0.362)$. Likewise, for microalbuminuria and macroalbuminuria groups, no significant difference was found $(p=0.435)$.

\section{Association between metabolic syndrome and albuminuria}

The correlation between components of metabolic syndrome and albuminuria can be seen in Table 4 . Spearman's test was used to measure the correlation between two unpaired variables. A significant association was found between systolic blood pressure and albuminuria, $p=0.000$ and $r=0.325$. Fasting blood glucose with albuminuria, $\mathrm{p}=0.01$ and $\mathrm{r}=0.223$. On the other hand, no significant association was found between diastolic blood pressure and albuminuria, $\mathrm{p}=0.153$, but a positive $r$ value $(r=0.125)$ means that although there was no statistically significant association, if diastolic blood pressure is higher, albuminuria will increase too. Likewise, between waist circumference with albuminuria, $\mathrm{p}=0.311$ but with a positive $\mathrm{r}$ value $(\mathrm{r}=0.089)$. The same goes with hypertriglyceridemia with albuminuria, $\mathrm{p}=0.727$ and $\mathrm{r}=0.031$. Even so, association of low HDL and albuminuria found $p=0.771$ and $r$ value $=-0.025$ mean that the lower of HDL will increase albuminuria.

Table 4. Correlation between components of metabolic syndrome and albuminuria

\begin{tabular}{lcc}
\hline $\begin{array}{l}\text { Components of metabolic } \\
\text { syndrome }\end{array}$ & $\mathbf{r}$ & $\mathbf{p}$ \\
\hline Waist circumference & 0.089 & 0.311 \\
Systolic BP & $0.325^{* *}$ & $0.000^{*}$ \\
Diastolic BP & 0.125 & 0.153 \\
HDL & -0.025 & 0.771 \\
Triglyceridemia & 0.031 & 0.727 \\
Fasting blood glucose level & $0.223^{* *}$ & $0.010^{*}$ \\
\hline
\end{tabular}

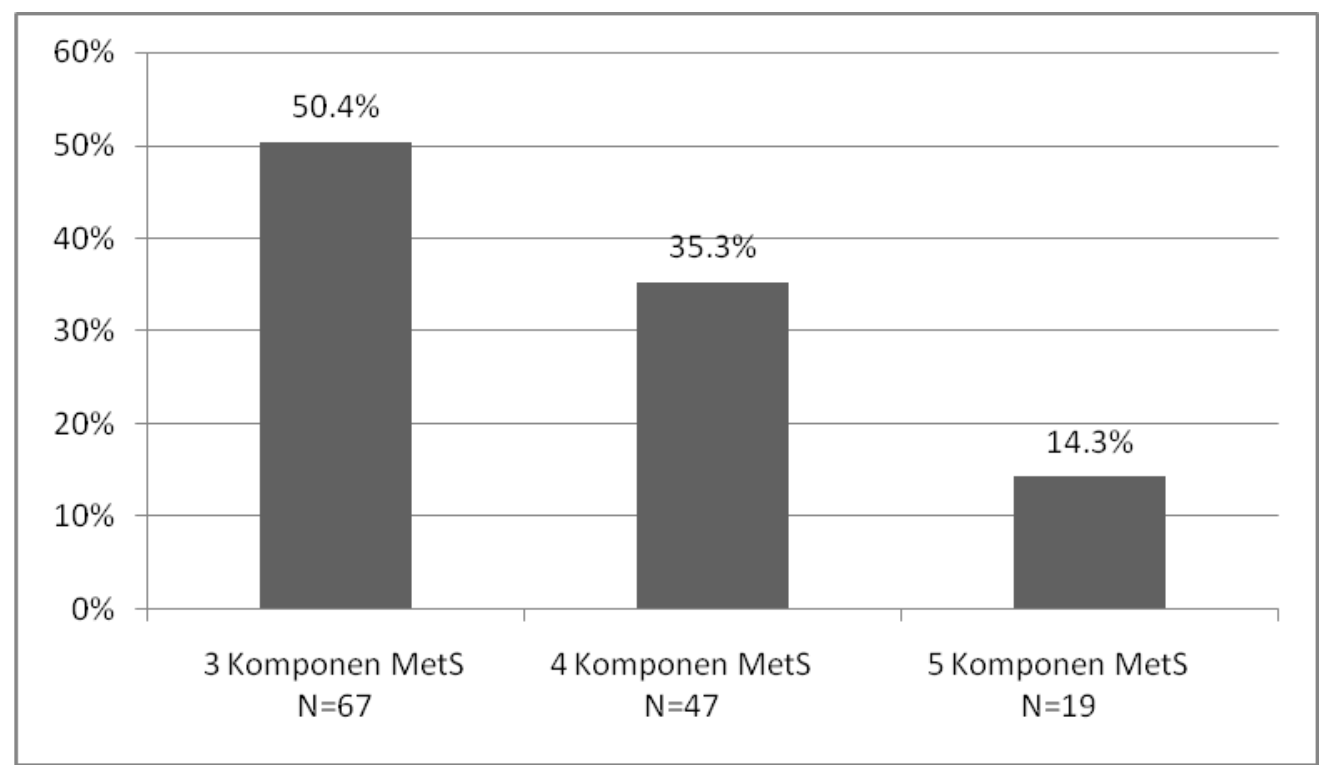

Figure 1. Proportion of metabolic syndrome based on the number of components 
Table 2. Characteristics of DMT2 with metabolic syndrome based on the classification of metabolic syndrome components

\begin{tabular}{lccccc}
\hline \multicolumn{1}{c}{ Variable } & Unit & $\begin{array}{c}\text { 3 ComponentMetS } \\
\mathrm{n}=19\end{array}$ & $\begin{array}{c}\text { 4Component MetS } \\
\mathrm{n}=19\end{array}$ & $\begin{array}{c}\text { 5 Component MetS } \\
\mathrm{n}=19\end{array}$ & P \\
\hline Age & year & $58(31-79)$ & $64(36-79)$ & $59(40-72)$ & 0.058 \\
\hline Duration of DM & year & $12(2-37)$ & $12(1-34)$ & $12(3-22)$ & 0.965 \\
\hline BMI & $\mathrm{kg} / \mathrm{m} 2$ & $29.17(24.09-40.61)$ & $28.72(22.48-38.02)$ & $29.75(24.98-45.91)$ & 0.570 \\
\hline Systolic BP & $\mathrm{mmHg}$ & $120(100-170)$ & $130(110-170)$ & $140(130-170)$ & $0.000 *$ \\
\hline Diastolic BP & $\mathrm{mmHg}$ & $80(60-95)$ & $80(70-110)$ & $85(78-110)$ & $0.000^{*}$ \\
\hline Waist size & $\mathrm{cm}$ & $94(80-121)$ & $96(81-120)$ & $95(80-118)$ & 0.898 \\
\hline Fasting Blood Glucose Level & $\mathrm{mg} / \mathrm{dL}$ & $152(65-409)$ & $177(85-418)$ & $188(101-427)$ & 0.227 \\
\hline Post Prandial Glucose Level & $\mathrm{mg} / \mathrm{dL}$ & $227(104-749)$ & $248(104-555)$ & $253(111-641)$ & 0.919 \\
\hline HbA1C & $\%$ & $8(5-18)$ & $8(5-113)$ & $9(7-12.2)$ & 0.454 \\
\hline Total Cholesterol & $\mathrm{mg} / \mathrm{dL}$ & $191(104-285)$ & $198(127-318)$ & $221(137-282)$ & 0.183 \\
\hline LDL & $\mathrm{mg} / \mathrm{dL}$ & $117(48-254)$ & $118(58-248)$ & $139(51-201)$ & 0.273 \\
\hline TG & $\mathrm{mg} / \mathrm{dL}$ & $123(63-356)$ & $183(58-484)$ & $203(153-388)$ & $0.000^{*}$ \\
\hline HDL & $\mathrm{mg} / \mathrm{dL}$ & $46(32-74)$ & $41(13-61)$ & $39(23-49)$ & $0.000^{*}$ \\
\hline Hb & $\mathrm{g} / \mathrm{dL}$ & $14(10-16.2)$ & $14(10.2-16.2)$ & $13(12-16)$ & 0.598 \\
\hline BUN & $\mathrm{mg} / \mathrm{dL}$ & $15(7.1-52)$ & $15(5-28)$ & $12(8-24)$ & 0.859 \\
\hline Creatinin serum & $\mathrm{mg} / \mathrm{dL}$ & $1(0.4-1.24)$ & $1(0.60-1.3)$ & $1(0.4-1.1)$ & 0.404 \\
\hline Albuminuria & $\mu \mathrm{g} / \mathrm{mg}$ & $14(1-983)$ & $7(1-183)$ & $122(1-1364)$ & $0.002 *$ \\
\hline & $\mathrm{kreat}$ & & & & \\
\hline
\end{tabular}

Table 3. Characteristics of DMT2 with metabolic syndrome based on albuminuria classification

\begin{tabular}{|c|c|c|c|c|c|}
\hline Variable & Unit & $\begin{array}{c}\text { Normo albumin- } \\
\text { uria } n=87\end{array}$ & $\begin{array}{l}\text { Mikro albuminuria } \\
n=36\end{array}$ & $\begin{array}{l}\text { Makro albumin- } \\
\text { uria } n=10\end{array}$ & $\mathrm{P}$ \\
\hline Age & year & $59(33-79)$ & $63(31-75)$ & $57(40-69)$ & 0.330 \\
\hline Duration of DM & year & $12(1-37)$ & $12(1-32)$ & $10.5(3-22)$ & 0.884 \\
\hline BMI & $\mathrm{kg} / \mathrm{m} 2$ & $29(22.48-38.02)$ & $29.53(24.98-45.91)$ & $28.32(25.20-34.46)$ & 0.300 \\
\hline Systolic BP & $\mathrm{mmHg}$ & $125(100-165)$ & $132.5(100-170)$ & $130(110-160)$ & $0.024^{*}$ \\
\hline Diastolic BP & $\mathrm{mmHg}$ & $80(60-100)$ & $80(60-110)$ & $80(70-110)$ & 0.296 \\
\hline Waist size & $\mathrm{cm}$ & $94(80-121)$ & $95(80-114)$ & $101(90-118)$ & 0.321 \\
\hline Fasting Blood Glucose Level & $\mathrm{mg} / \mathrm{dL}$ & $161(64-418)$ & $159.5(78-427)$ & $159.5(118-409)$ & 0.807 \\
\hline Post Prandial Glucose Level & $\mathrm{mg} / \mathrm{dL}$ & $248(104-555)$ & $230.5(111-749)$ & $237(129-569)$ & 0.906 \\
\hline $\mathrm{HbA1C}$ & $\%$ & $8(5.7-14.2)$ & $8.75(5-18)$ & $8.1(6-12)$ & 0.254 \\
\hline Total Cholesterol & $\mathrm{mg} / \mathrm{dL}$ & $197(107-318)$ & $208(104-285)$ & $181.5(160-267)$ & 0.441 \\
\hline LDL & $\mathrm{mg} / \mathrm{dL}$ & $115(58-248)$ & $128.5(51-254)$ & $113.5(48-150)$ & 0.076 \\
\hline $\mathrm{TG}$ & $\mathrm{mg} / \mathrm{dL}$ & $153(58-484)$ & $158.5(79-361)$ & $156.5(102-256)$ & 0,970 \\
\hline HDL & $\mathrm{mg} / \mathrm{dL}$ & $42(13-74)$ & $44(23-66)$ & $44.5(36-56)$ & 0.881 \\
\hline Uric Acid & $\mathrm{mg} / \mathrm{dL}$ & $5.7(2.4-9.4)$ & $5.5(3.3-9.7)$ & $5.65(3.1-7.5)$ & 0.997 \\
\hline SGOT & $\mathrm{mg} / \mathrm{dL}$ & $25(8-59)$ & $29.5(9-62)$ & $21(13.1-51)$ & 0.575 \\
\hline SGPT & $\mathrm{mg} / \mathrm{dL}$ & $28(10-69)$ & $29.5(12-66)$ & $25.5(14-45)$ & 0.831 \\
\hline $\mathrm{Hb}$ & $\mathrm{g} / \mathrm{dL}$ & $14(10-16.2)$ & $13.9(10.2-16.2)$ & $13.8(12-14.5)$ & 0.764 \\
\hline BUN & $\mathrm{mg} / \mathrm{dL}$ & $15(5-36)$ & $12.8(6.3-52)$ & $15.5(7.1-23)$ & 0.778 \\
\hline Serum Creatinin & $\mathrm{mg} / \mathrm{dL}$ & $1(0.4-1.3)$ & $1(0.40-1.21)$ & $1(0.7-1)$ & 0.390 \\
\hline
\end{tabular}




\section{Discussion}

\section{Metabolic syndrome in DM type 2}

This study used IDF criteria in 2006 to determine metabolic syndrome. The results found that patients with 3 components of metabolic syndrome were $50.4 \%$, patients with 4 components of metabolic syndrome were $35.3 \%$, and patients with 5 components of metabolic syndrome were $14.3 \%$. Meanwhile, the study by Ford, et al. found that the prevalence of individuals with one component of metabolic syndrome was $71.2 \%$, two components $43.9 \%$, three components $23.7 \%$, four components $10.4 \%$, and five components $2.7 \% .^{5}$ Lea reported the component profile of the metabolic syndrome was $7.1 \%$ with one component, $92.9 \%$ with two components, $63.1 \%$ with three components, $33.3 \%$ with four components, and $13.1 \%$ with 5 components. ${ }^{6}$

The prevalence of metabolic syndrome is influenced by factors that can or cannot be modified. Many of these factors are interrelated, including age, gender, ethnicity/ race, obesity and fat distribution, diet and physical activity patterns, birth weight, genetics, endocrine factors, menopause or hormone replacement therapy, inflammation, alcohol, and comorbid factors (such as diabetes, hypertension, coronary artery disease). Nevertheless, the prevalence of metabolic syndrome can be increased due to the increasing prevalence of obesity and central obesity. ${ }^{7}$ Jorgenson examined the prevalence of metabolic syndrome in a population over 35 years old, found two different figures using different criteria, using WHO criteria the prevalence was $20.7 \%$, while using NCEP-ATP III criteria the prevalence was $17.9 \% .{ }^{8}$ Pranoto, et al. reported that the prevalence of metabolic syndrome based on NCEP-ATP III criteria was $34 \% .^{9}$ This is similar to the study by Adam, et al. that prevalence of metabolic syndrome was $33.4 \% .{ }^{10}$ The diagnosis of metabolic syndrome is based on the criteria of NCEP ATP III which are modified for Asian populations, if there are 3 out of the 5 criteria listed below: 1.Waist size for male $>90 \mathrm{~cm}$ and female $>80 \mathrm{~cm}$,

2.Increases of triglyceride level $>150 \mathrm{mg} / \mathrm{dL}$,

3.Decreases of HDL cholesterol level on male $<40 \mathrm{mg} / \mathrm{dL}$ and female $<50 \mathrm{mg} / \mathrm{dL}$,

4.Increases of blood pressure $>130 / 85 \mathrm{mmHg}$, 5 .Increases of fasting blood glucose level $>110 \mathrm{mg} / \mathrm{dL}$ or having diabetes. ${ }^{2}$

In contrast to the criteria for metabolic syndrome according to IDF in 2006, which stated a person has metabolic syndrome if he/she has central obesity (characterized by waist circumference $>90 \mathrm{~cm}$ in male and $>80 \mathrm{~cm}$ for female) plus 2 or more than 4 of the following components:

1.Triglyceride level $>150 \mathrm{mg} / \mathrm{dL}$ or being fat disorder treatment,

2.HDL level $<40 \mathrm{mg} / \mathrm{dL}$ on male and $<50 \mathrm{mg} / \mathrm{dL}$ on female or being fat disorder treatment,

3. Systolic blood pressure $>130 \mathrm{mmHg}$ or diastolic $>85$ $\mathrm{mmHg}$ or being hypertension treatment,

4.Fasting blood glucose level $>100 \mathrm{mg} / \mathrm{dL}$ or being DM type 2 treatment. ${ }^{1}$

The proportion for each component of metabolic syndrome in this study found $52.6 \%$ subjects with hypertension, 56.4\% subjects with hypertriglyceridemia,
$54.9 \%$ subjects with low HDL cholesterol, $100 \%$ central obesity, and $100 \%$ diabetes mellitus. This study shows that all subjects have central obesity, this is because in determining the metabolic syndrome this research used IDF criteria in 2006 where a person is said to have metabolic syndrome if he/she has central obesity marked by waist circumference $>90 \mathrm{~cm}$ in men and $>80 \mathrm{~cm}$ for women, plus 2 or more than 4 other components of metabolic syndrome. All subjects in this study also had diabetes mellitus because the subject population was taken from people with DMT2.

These results are similar with other researches. Research conducted by Pranoto, et al. reported the proportion of central obesity of $85.29 \%$, hypertriglyceridemia $85.29 \%$, low HDL cholesterol 52.94\%, increased systolic blood pressure $82.35 \%$, increased diastolic blood pressure $55.88 \%$, and increased fasting blood glucose $41.17 \%$ (9). Meanwhile, research conducted by Michel in 2006 on 476 metabolic syndrome populations found central obesity $(14.3 \%)$, hypertriglyceridemia $(17.0 \%)$, increased blood pressure or those using ant1 hypertension (80.7\%), increased blood glucose levels fasting or those using antidiabetes therapy $(37.2 \%){ }^{11}$

\section{Albuminuria in DM type 2}

The results from 133 DMT2 patients, $65.4 \%$ of patients have normoalbuminuria, $27.1 \%$ microalbuminuria, and $7.5 \%$ macroalbuminuria. It is in line with research by Tseng on 549 DMT2 patients, which found $45.7 \%$ DMT2 patients with normoalbuminuria, 44.1\% patients with microalbuminuria, and $10.2 \%$ patients with macroalbuminuria, ${ }^{12}$ meanwhile the study by Chiowanich of 2231 DMT2 patients, found $63.4 \%$ patients with normoalbuminuria, $27.5 \%$ patients with microalbuminuria, and $9 \%$ patients with macroalbuminuria. ${ }^{13}$

Microalbuminuria can be an etiology or complication of vascular disease. STENO hypothesis said that leakage of albumin into the urine is a reflection of extensive vascular damage. This hypothesis links endothelial dysfunction with vascular albumin leakage. In some ways, the kidneys are the window to the body's vascular system. Renal leakage can reflect the permeability of the overall vascular system. ${ }^{14}$ A significant difference was found in systolic blood pressure with albuminuria $p=0.024$. Whereas in age, duration of $\mathrm{DM}$, body mass index (BMI), diastolic blood pressure, waist circumference, fasting blood glucose (FBG), post prandial glucose level, HbA1C, total cholesterol, LDL, triglycerides, $\mathrm{HDL}, \mathrm{Hb}, \mathrm{BUN}$, and serum creatinine no meaningful difference obtained. Based on the MannWhitney test, there was a significant difference in systolic blood pressure between the normoalbuminuria and microalbuminuria groups, $\mathrm{p}=0.007$. However, between normoalbuminuria and macroalbuminuria groups, there was no significant difference. Likewise, for microalbuminuria and macroalbuminuria groups, no significant difference was found.

Published data from cross sectional studies show the prevalence of microalbuminuria in hypertensive populations ranging from $4.7 \%$ to $40 \%$, depending on the severity of hypertension and comorbidity. Research by de Melo $^{15}$ confirmed the Nogueira study, which showed that there was an association between blood pressure changes and the incidence of diabetes mellitus with an increase 
of albuminuria in individuals with hypertension. This suggests that efforts to achieve adequate blood pressure and glycemic control must be sought, with the aim of reducing albuminuria excretion and consequently preventing evolution towards target organ damage and decreasing morbidity and mortality. ${ }^{15}$

\section{Correlation between metabolic syndrome and albuminuria}

This study found a significant association between systolic blood pressure and albuminuria, $\mathrm{p}=0.000$ and $r=0.325$. Fasting blood glucose with albuminuria, $p$ $=0.01$ and $\mathrm{r}=0.223$. This is consistent with the results shown by research conducted by Hao, et al. ${ }^{4}$ as well as by Palaniappan, et al. ${ }^{16}$ Whereas in diastolic blood pressure, waist circumference, low HDL, and hypertriglyceridemia, there was no significant association.

Study by Hao, et al. showed a significant relationship between metabolic syndrome and albuminuria. This study also stated that blood pressure and obesity individually have an association with ural microalbumin. ${ }^{4}$ In the study of Palaniappan, et al., a strong positive relationship was found between the components of metabolic syndrome and microalbuminuria in both male and female populations. From this research it shows that high glucose levels and blood pressure are the most influential components on the occurrence of microalbuminuria. ${ }^{16}$ Study by Tseng showed that TG levels increased with increasing albuminuria. TG levels differed significantly between the three groups of albuminuria and correlated with albuminuria (ACR) for the entire albuminuria range. ${ }^{12}$

Numerous studies have shown that lipid abnormalities can initiate glomerular injury and increase the development of existing glomerular disease. The final pathway for most of these diseases is generally the development of glomerulosclerosis. The mechanism that associate hypercholesterolemia with the development of glomerular disease is thought to be the same as the influence of high cholesterol levels which cause atherosclerosis. ${ }^{17}$

Glomerular cells have LDL receptors, mesangial, and glomerular epithelial cells that can internalize atherogenic lipoproteins through receptor or non-receptor intermediate mechanisms. Infiltration of atherogenic lipoproteins into glomerular endothelium and mesangial cells can initiate a cascade of events including expression of adhesion molecules, production of monoattractant monocytes, and reactive release of oxygen species, resulting in initial glomerular injury. ${ }^{12}$

In the study of Zoppini with a large 5-year cohort study involving 1987 outpatient DMT2 patients, it showed that high plasma HDL levels were strongly associated with a reduction in the incidence of CKD (GFR $\leq 60 \mathrm{~mL} / \mathrm{min}$ / $1.73 \mathrm{~m} 2$ ). Similar results in a study by Ravid showed low plasma HDL levels predicted the development of microalbuminuria in 574 people with DMT2 during a 7-8 year follow-up. ${ }^{18}$

The biological mechanisms underlying HDL in protecting the development and progression of CKD in people with DMT2 are poorly understood. Actually, HDL is involved in reverse transportation (reversal) of cholesterol, but HDL can also use several other effects, including antioxidants, anti-inflammatory, anti-thrombotic effects and protective effects of blood vessels. All of these beneficial vascular effects can also play a role at the level of kidney microcirculation, so it might explain the lower risk of CKD in the presence of higher HDL levels. ${ }^{18}$

Finally, pharmacological interventions that are known to be effective in preventing or delaying the development of cardiovascular disease in people with DMT2, including close monitoring of blood pressure, LDL levels and glucose, can reduce the development and progression of kidney disease. The potential clinical implications of this finding for patient care is that in people with DMT2 with low plasma HDL levels, physicians must be more aware of the greater possible risk for developing CKD, and that pharmacological treatment aimed specifically at increasing plasma HDL levels may be a promising approach to reducing risk of development and progression of kidney disease.

\section{Conclusion}

There is a significant association between systolic blood pressure and fasting blood glucose level with albuminuria. Whereas in diastolic blood pressure, waist circumference, low HDL, and hypertriglycerida, there was no significant association. In the future, it is necessary to control the components of the metabolic syndrome, so that the risk for cardiovascular disease complications marked by albuminuria can be reduced. The high proportion of microalbuminuria in DMT2 patients has led to the need for increased attention from health care providers to conduct microalbuminuria screening tests for each DMT2 patients.

\section{Conflict of Interest}

The author stated there is no conflict of interest

\section{References}

1. IDF. The IDF concensus worldwide definition of the metabolic syndrome http://www.idf.org/2006

2. Tjokroprawiro A. The metabolik syndrome. Surabaya: Universitas Airlangga; 2008.

3. Cirillo M LM, Mancini M. Low muscular mass and overestimation of microalbuminuria by urinary albumin/creatinine ratio. Hypertension Journal 2006;47:56-61.

4. Hao Z KT, Takasaki S The association between microabuminuria and metabolic syndrome in the general population in Japan http://www. naika.or.jp/imindex.html.2006

5. Ford ES GW, Dietz WH Prevalence of Metabolic Syndrome Among US Adult. The Third National Health and Nutrition Examination Survey. 2002;287.

6. MS L. Asosiasi Sindroma Metabolik Dengan Makroangiopati Pada Populasi Diabetes Mellitus Tipe 2. In: Airlangga FKU, editor. Penelitian Karya Akhir Bagian - SMF Ilmu Penyakit Dalam. Surabaya2007.

7. Byrne CDW, Sarah S The Metabolik Syndrome. Chichester, West Sussex: John Wiley 'n Sons, Ltd. ; 2005.

8. Jorgensen ME BP, Gyntelberg F Prevalence of the metabolic syndrome among the inuit in the Greenland. Diabetes Medicine 2004;21:1237-42.

9. Pranoto A KU, Tjokroprawiro A. Metabolic syndrome as observed in Surabaya. Naskah Lengkap Surabaya Metabolic Syndrome 2005; 1:245-7.

10. JMF A. Dislipidemi pada sindroma metabolik. Bandung: Perkeni; 2006.

11. Michel ES FT, Jacques B. Metabolic syndrome and age-related progression of aortic stiffness. Journal of the American College of Cardiology 2006;47:72-5.

12. Tseng C. Differential dyslipidemia associated with albuminuria in type 2 diabetic patients in Taiwan. Clinical Biochemistry 2009;42:1019.

13. Chiowanich P KT, Oravivattanaku S. Prevalence and risk factors of 
microalbuminuria in patient with diabetic mellitus at northern part referral hospital in Thailand. Diabetes \& Metabolic Syndrome: Clinical Research \& Reviews 2009;3:152.

14. MR W. Microalbuminuria and Cardiovascular Disease Clin J Am Soc Nephrol. 2007;2:581-90.

15. De Melo ROV, Toledo, J.Y.T., Souza, D.R.S. Factors Associated with Impaired Urinary Albumin Excretion in Hypertensive Individuals Albuminuria and Hypertension. International Journal of Cardiology. 2009;1.

16. Palaniappan L CM, Fortmann SP Association between micro albuminuria and the metabolic syndrome: NHANES III. Am J Hypertensi. 2003;16:952-8.

17. Wanner C QT. Dyslipidemia and renal disease: pathogenesis and clinical consequences. Current Opinion in Nephrology and Hypertension 2001;10:195-201.

18. Zoppini G, Targher, G., Chonchol, M. Higher HDL cholesterol levels are associated with a lower incidence of chronic kidney disease in patients with type 2 diabetes. Nutrition, Metabolism \& Cardiovascular Diseases 2009;19:580. 